\title{
Prescribing Buprenorphine for Opioid Use Disorders in the ED: A Review of Best Practices, Barriers, and Future Directions
}

This article was published in the following Dove Press journal: Open Access Emergency Medicine

\author{
Scott S Cao' \\ Samuel I Dunham' \\ Scott A Simpson (iD ${ }^{1,2}$ \\ 'University of Colorado School of \\ Medicine Anschutz Medical Campus, \\ Aurora, CO, USA; ${ }^{2}$ Psychiatric \\ Emergency Services, Denver Health \\ Medical Center, Denver, CO, USA
}

Correspondence: Scott A Simpson Denver Health Medical Center, 777 Bannock St, MC 0I 16, Denver, CO 80204, USA

Tel +| 303-602-722|

$\mathrm{Fax}+1$ 303-602-7222

Email scott.simpson@dhha.org

\begin{abstract}
ED-initiated addiction treatment holds promise for enhancing access to treatment for those with opioid use disorder (OUD). We present a literature review summarizing the evidence for buprenorphine induction in the ED including best practices for dosing, follow-up care, and reducing implementation barriers. A literature search of Pubmed, PsychInfo, and Embase identified articles studying OUD treatment in the ED published after 1980. Twenty-five studies were identified including eleven scientific abstracts. Multiple studies suggest that buprenorphine induction improves engagement in substance treatment up to 30 days after ED treatment. Many different induction protocols were presented, but no particular approach was best supported as criteria for induction and initial dosing vary widely. Similarly, transition of care models focused on either a "hub and spoke" model or "warm hand-offs" model, but no studies compared these approaches. Common barriers to implementing induction programs were provider inexperience, discomfort with addiction treatment, and limited time during the ED visit. No studies described the number of EDs offering induction. While ED buprenorphine induction is safe and enhances adherence to addiction treatment, uncertainty persists in how to best identify patients needing treatment, how to initiate buprenorphine, and how to enhance follow-up after ED-initiated treatment.
\end{abstract}

Keywords: buprenorphine, opioid use disorder, opioid overdose, emergency department

\section{Introduction}

Emergency services are well-positioned to provide effective treatment to patients with opioid use disorder (OUD). There is a significant need to deliver OUD treatment: in 12 months from February 2018 to February 2019, 69,209 people died in the United States from opioid overdose. ${ }^{1}$ Every year, an additional 11 million American misuse opioids by taking the medication in a manner other than prescribed. ${ }^{2}$ Opioid-related emergency department (ED) visits in the United States have doubled since 2010; these visits often involve treatment after an overdose or other substance abuse-related complication. ${ }^{3}$ Many more visits are complicated by concurrent opioid misuse, as when patients with OUD awaiting hospital admission require management of withdrawal symptoms while still in the ED.

OUD is a biological and behavioral disorder characterized by signs and symptoms that reflect compulsive, prolonged self-administration of opioid substances that are used for no legitimate medical purpose or, if another medical condition is present that requires opioid treatment, that are used in doses greatly in excess of the amount needed for that medical condition. ${ }^{4}$ Patients with OUD often spend significant time acquiring, using, and recovering from opioid use while suffering 
impairment across multiple personal, occupational, and health domains. Illegal opioid use can be detected with a high degree of sensitivity with a one question screener "In the past year, how often have you used prescription drugs for non-medical reasons or illegal drugs?"5 Patients who report misuse at least once in the past year merit further assessment. Predicting the risk of potential misuse of prescribed opioids requires longer screening tools such as the five question Opioid Risk Tool. ${ }^{6}$

Traditionally the standard of care for OUD has been daily dosing of methadone as part of a robust addiction treatment program. As a full mu-opioid agonist, methadone provides patients relief from withdrawal and inhibits the euphoria induced by intravenous heroin use. The routine of daily dosing provides behavioral structure and obviates the continual seeking and recovering from opioids that causes significant social impairment in OUD. Additional treatments include psychotherapy to aid in relapse prevention, management of concurrent medical illnesses (such as hepatitis $\mathrm{C}$ virus), and treatment for co-occurring psychiatric disorders. Methadone maintenance treatment reduces patients' risk of infectious disease, social dysfunction, and death due to opioid addiction. ${ }^{7,8}$ However, prescribing methadone for daily dosing must occur within a highly monitored setting to avoid the risk of diversion or adverse side effects such as over-sedation. ${ }^{9,10}$ The need to observe patients for extended periods after their first dose and the risk of subsequent sedation make methadone problematic for treating OUDs in the ED setting.

The availability of the partial mu-opioid agonist buprenorphine has made it possible to safely treat opioid withdrawal and initiate OUD treatment from the ED with greater success than motivational interviewing and referral to treatment alone. 7 Buprenorphine's partial agonism allows a safer therapeutic index that achieves symptomatic resolution of opioid withdrawal without methadone's associated risk of overdose, particularly in the setting of additional opioid use. ${ }^{11,12}$ Buprenorphine is often combined with naloxone for outpatient maintenance therapy; the naloxone addition is not bioavailable when taken orally and has no impact on the therapeutic efficacy of the drug. Rather, naloxone is added as a deterrent to misuse, as naloxone becomes bioavailable only once injected to induce immediate and uncomfortable withdrawal. ${ }^{11}$

Since the publication of a landmark trial demonstrating the efficacy of buprenorphine induction for ED patients with OUDs, EDs across the country have developed protocols for facilitating buprenorphine induction. ${ }^{13}$
D'onofrio et al demonstrated that among opioid dependent patients, induction of buprenorphine in the ED compared to control resulted in higher engagement in addiction treatment. However, there remains a great deal of variation in ED practice for patients with OUD, and subsequent articles have added nuance to inform clinical practice. A significant gap in providing ED-based induction still remains: one analysis suggested that only one in three patients who had screened positive for OUD actually receive effective treatment for OUD. ${ }^{14}$

This review summarizes the evidence and best practices for initiating buprenorphine treatment for OUDs in the ED. We also identify barriers to implementing EDbased buprenorphine induction, limitations in the extant literature, and opportunities for enhancing the care of these patients in the ED.

\section{Methods}

A search of the Pubmed, PsychInfo, and Embase databases was conducted to identify articles related to OUD treatment in the emergency department using a combination of terms "buprenorphine" and "emergency service, hospital." References from included articles and similar articles sections on Pubmed were utilized to identify additional literature. Results were narrowed to include English-titled articles published after 1980 through March 2020. Finally, the authors selected articles that included all three elements: OUD treatment, emergency department, and buprenorphine. Study quality was assessed using the Cochrane risk of bias for randomized controlled trials and the Newcastle-Ottawa Scale for cohort studies. ${ }^{15,16}$ Two authors independently rated all of the trial and cohort studies; inter-rater reliability was assessed using the kappa statistic. ${ }^{17}$ Disagreements were resolved by consensus to produce a final assessment.

\section{Results}

\section{Article Selection}

An initial database search yielded 818 academic products, and of those studies, 25 were applicable to this report. These studies included 14 peer-reviewed manuscripts and 11 scientific abstracts. Figure 1 illustrates the article selection process. ${ }^{18}$ Of the 14 manuscripts, two were randomized controlled trials and seven were cohort studies. The inter-rater reliability was $91 \%$ (kappa $=0.77$, suggesting substantial agreement) in scoring cohort studies and $100 \%$ in scoring the randomized trials. ${ }^{17}$ 


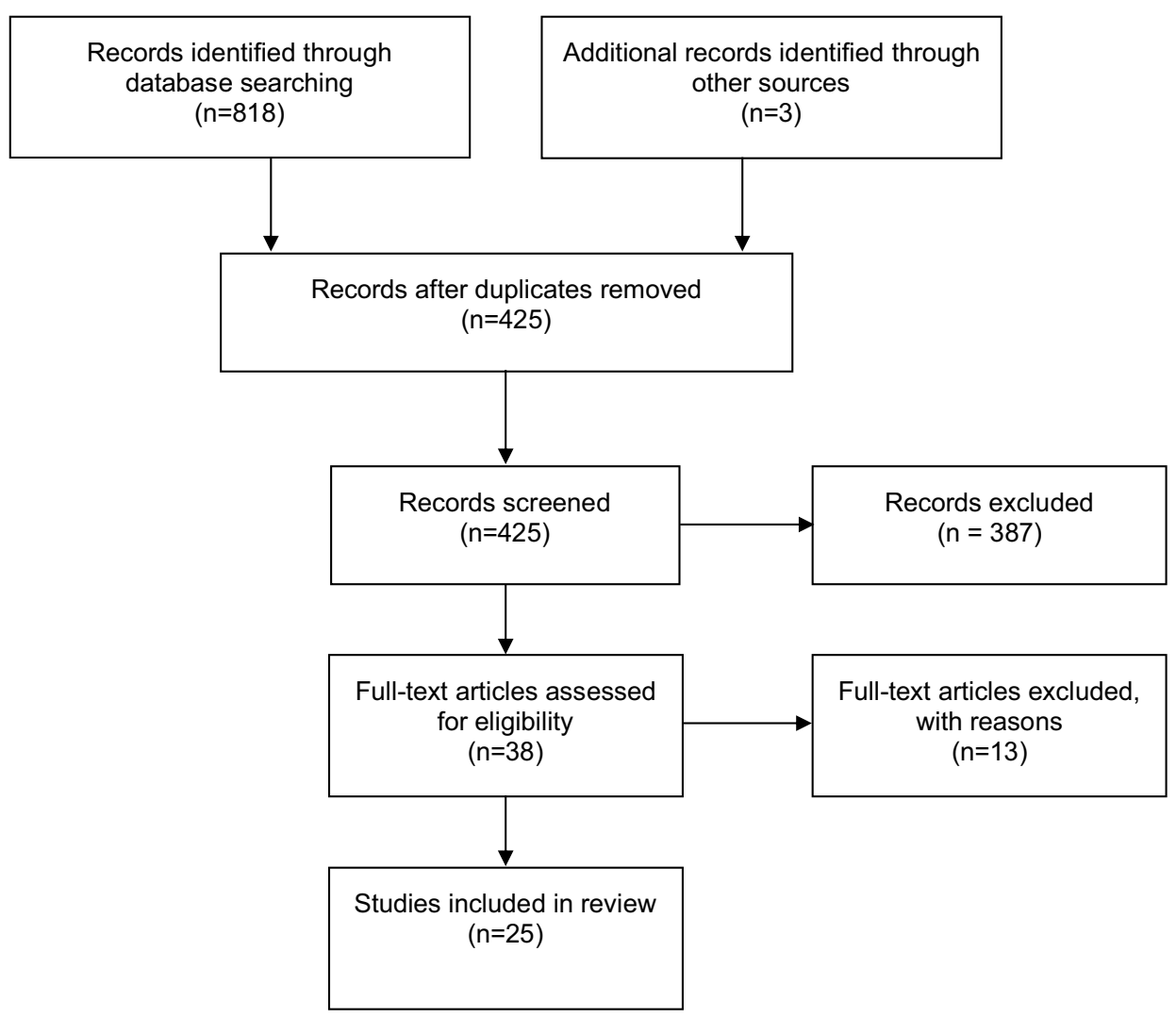

Figure I Study selection process.

\section{Effectiveness of Buprenorphine Induction for OUD in the ED}

After induction, the most commonly studied outcome of interest is initial patient follow-up at an outpatient appointment after discharge from the ED and whether these patients are still enrolled in outpatient treatment at 30 days. Initial visit follow-up rates ranged from $63 \%$ to $83 \%^{19-23}$ compared to $38 \%{ }^{21}$ among control conditions. Follow-up rates at 30 days ranged from $47 \%$ to $78 \%$, which is higher than the $7.6 \%$ to $37 \%$ range for controlgroup patients in all studies. ${ }^{13,19-22}$

Two randomized trials evaluated the efficacy of buprenorphine induction in the ED. D'Onofrio et al randomized 328 ED patients with OUD and found patients receiving buprenorphine induction were more likely to be retained in treatment at 30 days $(95 \%)$ than those in a referral to treatment $(37 \%)$ or enhanced psychotherapeutic intervention (45\%) control cohorts. ${ }^{13}$ Patients receiving buprenorphine followed up in a primary care setting. The buprenorphine intervention was associated with less frequent use of inpatient addiction services as well, but the incidence of negative urine toxicology tests was similar across cohorts. Subsequent analyses of the trial have revealed that buprenorphine induction proved cost-effective, ${ }^{24}$ although retention rates did not vary among groups by 6 months. ${ }^{25} \mathrm{~A}$ second trial randomized 26 ED patients in opioid withdrawal to receive buprenorphine or clonidine treatment along with a discharge prescription and follow-up instructions. ${ }^{21}$ Clonidine is a nonopioid sedative used for withdrawal management. Patients in the buprenorphine cohort were more likely to be receiving agonist treatment at one month $(62 \%)$ than the clonidine cohort (8\%). Table 1 details the quality of these studies.

Seven cohort studies described the outcomes from buprenorphine induction programs. The highest quality cohort study is a retrospective analysis of 219 patients who underwent induction in an urban Level I Trauma Center; $75 \%$ of patients used intravenous opioids, and the mean total dose received in the ED was $8 \mathrm{mg} .{ }^{20}$ Followup retention at 30 days was $49 \%$. The investigators found a decrease in median length of ED stay of $40 \%$ for induction patients since the beginning of the program, which suggests that familiarity with the practice among clinicians may reduce the impact of long induction stays for other patients. No other medical outcomes including infection incidence or overdoses were assessed. Another 


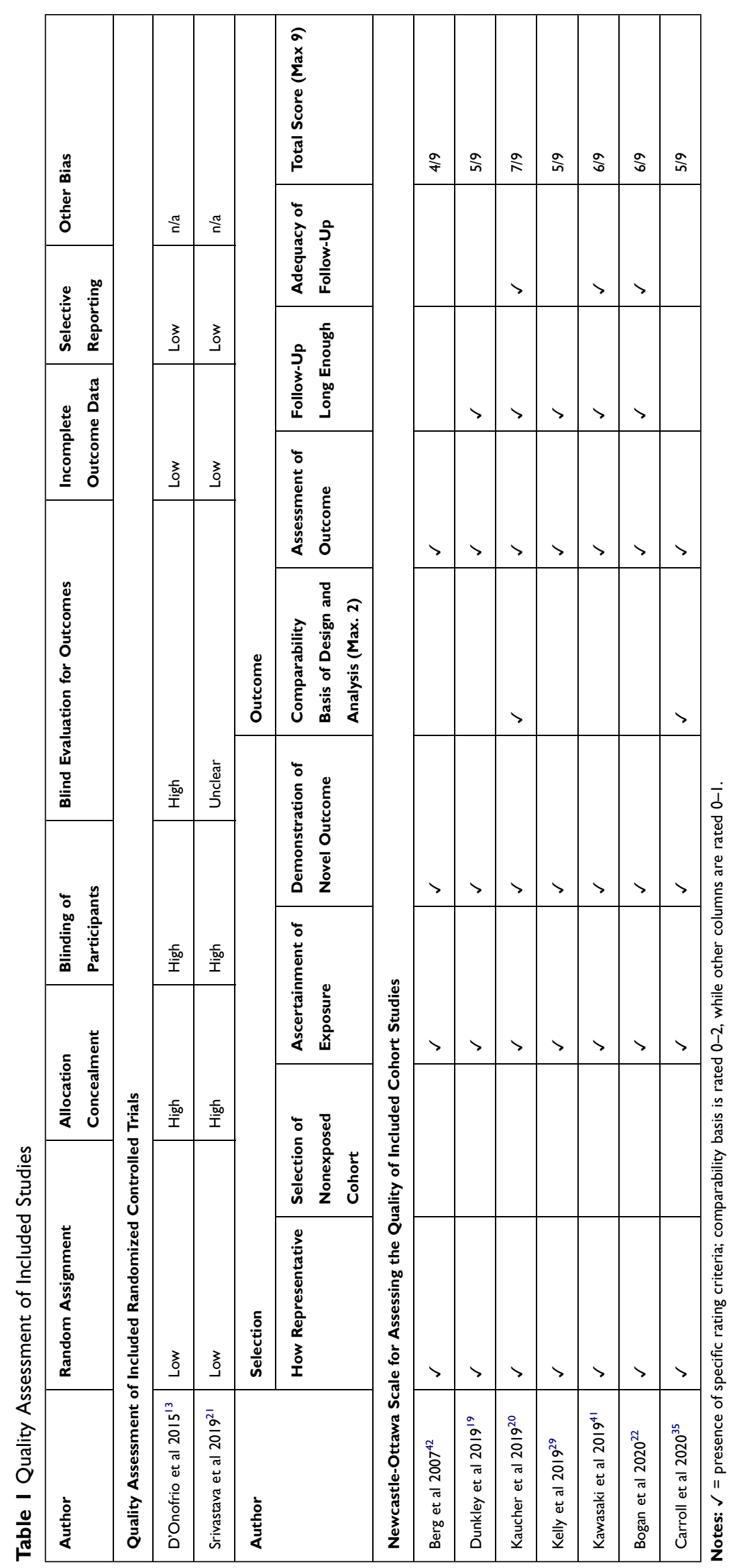


high quality cohort study described outcomes among 231 ED patients among multiple sites who were induced with a single dose of buprenorphine $8 \mathrm{mg}^{22}$ In this study, $77 \%$ of patients arrived to next-day appointments, and $60 \%$ were retained in treatment at 30 days. A third cohort study of note described the implementation of a multisite buprenorphine induction program across 12 sites including 2 emergency departments. They found an overall retention rate of $43 \%$ at 6-month follow-up, although these numbers exclude patients who receiving an induction but failed the first follow-up appointment. Study outcomes and quality of additional cohort studies are described in Table 1.

\section{Identification of Patients for Induction}

Clinical guidelines suggest that patients should have a diagnosis of OUD and exhibit at least mild acute opioid withdrawal. ${ }^{26}$ Among the research literature, there are variable inclusion and exclusion criteria for providing EDbased induction. Inclusion criteria have most often been a diagnosis of OUD, ${ }^{13,19,21-23,27}$ age over $16^{21}$ or $18,{ }^{13,27}$ a positive urine test for opioids, ${ }^{13}$ recent or multiple visits related to overdose, ${ }^{23}$ intoxication, ${ }^{23}$ or admission to an ED observation unit. ${ }^{19}$ Exclusion criteria were pregnancy, ${ }^{13,21,23,27}$ current enrollment in an OUD treatment program, ${ }^{13,21,23,27}$ abuse of benzodiazepines or alcohol, ${ }^{21,23}$ liver disease, ${ }^{21}$ critically ill patients, ${ }^{13}$ active suicidality, ${ }^{13}$ police custody, ${ }^{13}$ or an inability to communicate due to dementia or psychosis. ${ }^{13}$ While ED studies have often excluded pregnant patients, research outside of emergency settings has shown that buprenorphine is safe and effective for pregnant patients. ${ }^{28}$

Few studies examined additional clinical factors associated with improved treatment outcomes. Two cohort studies reported on factors associated with a decreased likelihood of remaining in treatment. These factors were unstable housing, ${ }^{19}$ unemployment, ${ }^{19}$ poor social support system, ${ }^{19}$ heroin use, ${ }^{19}$ lack of transportation, ${ }^{20}$ and receiving a referral to follow-up care to a different health system. ${ }^{29}$

\section{Optimal Procedure for Buprenorphine Induction}

Studies offered general guidance for dosing and timing. Most protocols use the Clinical Opioid Withdrawal Scale (COWS) to assess withdrawal severity. The COWS is a clinician-administered tool for assessing a patient's level of opioid withdrawal by rating 11 commonly seen opioid withdrawal symptoms. ${ }^{30}$

Clinical assessment of withdrawal is imperative to ensuring that patients are in withdrawal to induction and decreasing the risk of precipitated withdrawal. Precipitated withdrawal is a particularly worrisome adverse effect in the ED. Precipitated withdrawal occurs when a patient takes buprenorphine too soon after another opioid agonist, and the patient experiences an immediate withdrawal syndrome due to displacement of that agonist by buprenorphine, a partial agonist. Precipitated withdrawal can largely be avoided by only commencing induction in a patient with objective evidence of opioid withdrawal on physical examination or by adhering an opioid withdrawal scale. There are no strict cutoff criteria based on COWS score; Table 2 reports cutoffs used by different studies. Precipitated withdrawal is most concerning among pregnant patients, for whom clinicians should feel utterly confident as to the presence of acute opioid withdrawal before initiating buprenorphine. Patients misusing long-acting opioids may evince opioid withdrawal yet remain at risk for precipitated withdrawal. In these cases, the clinician should have a discussion of risks and benefits with the patient.

Just as there are no concrete rules for initiation based on COWS scores, neither is there clear guidance for the initial dosing of buprenorphine. In studies, initial induction doses ranged from $2 \mathrm{mg}$ to $4 \mathrm{mg}$ and up to a maximum of $16 \mathrm{mg}$ over the ED course. 19,20,22,23,27,31-33 Timing of buprenorphine administration included waiting 24 hours after the last known use of extended-release opioids, ${ }^{27,31,32,34} 6-12$ hours after the last known use of short-acting opioids, ${ }^{27,32,34}$ and 48 hours following the use of methadone after that agent had been substantially tapered. ${ }^{34}$ No studies compared different induction regimens or different practices for subsequent dosing, so the optimal induction regimen for improving outcomes remains unknown. Table 2 describes specific induction regimens reported in the literature.

One study described immediate initiation of buprenorphine after opioid overdose reversal with naloxone in the field by trained emergency medical technicians (EMT). The investigators did not report any complications with subsequent induction of buprenorphine once the patients reached the ED. This novel two-step induction suggests that immediate administration of buprenorphine after naloxone is a safe and of value for emergency medical service clinicians. ${ }^{35}$

In summary, an initial dose of $4 \mathrm{mg}$ appears to be welltolerated and effective for starting patients on buprenorphine therapy for OUD; an additional 4-8 mg may be administered if the patient continues to experience withdrawal symptoms 
Table 2 Published Protocols for Emergency Department Buprenorphine Induction

\begin{tabular}{|c|c|c|c|c|c|}
\hline Author & Method & $\begin{array}{l}\text { Clinical } \\
\text { Assessment } \\
\text { and Induction } \\
\text { Threshold }\end{array}$ & Dosing & Plan for Follow-Up & Outcomes \\
\hline $\begin{array}{l}\text { Berg et al } \\
2007^{42}\end{array}$ & $\begin{array}{l}\text { Retrospective cohort study } \\
\text { of I } 58 \text { patients investigating } \\
\text { adverse outcomes of } \\
\text { buprenorphine when } \\
\text { treating patients with OUD } \\
\text { in the ED }\end{array}$ & $\begin{array}{l}\text { - } \text { soWs } \\
\text { - oOWs }\end{array}$ & $\begin{array}{l}\text { Initial: } 0.3 \mathrm{mg}- \\
0.9 \mathrm{mg} \text { IM } \\
\text { Maximum: Not } \\
\text { specified }\end{array}$ & $\begin{array}{l}\text { - Patients were given IM } \\
\text { doses of buprenorphine } \\
\text { after being evaluated with } \\
\text { either SOWS or OOWS } \\
\text { to assess for withdrawal } \\
\text { symptoms } \\
\text { - The buprenorphine group } \\
\text { was compared to } \\
\text { a symptom management } \\
\text { group and a group that did } \\
\text { not receive pharmacologi- } \\
\text { cal intervention }\end{array}$ & $\begin{array}{l}8 \%(7 / 88) \text { of patients who } \\
\text { were treated with } \\
\text { buprenorphine had a drug- } \\
\text { related return to the ED } \\
\text { within } 30 \text { days compared } \\
\text { with } 17 \%(5 / 29) \text { of patients } \\
\text { who received only } \\
\text { symptomatic treatment }\end{array}$ \\
\hline $\begin{array}{l}\text { D'Onofrio } \\
\text { et al } \\
2015^{13}\end{array}$ & $\begin{array}{l}\text { RCT of } 329 \text { patients using } \\
\text { three different treatments } \\
\text { arms to assess patient } \\
\text { retention in MAT after ED } \\
\text { treatment }\end{array}$ & 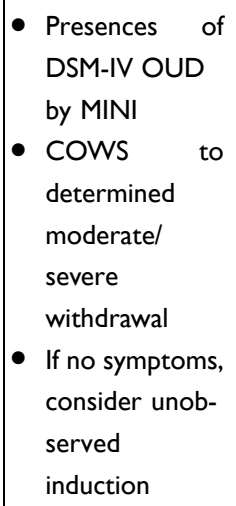 & $\begin{array}{l}\text { Initial: } 8 \mathrm{mg} \\
\text { on day one } \\
\text { Follow up: } \\
16 \mathrm{mg} \text { on days } \\
\text { two and three }\end{array}$ & $\begin{array}{l}\text { - Scheduled appointment } \\
\text { with hospital primary } \\
\text { care within } 72 \text { hours } \\
\text { - Prescribed } 16 \mathrm{mg} \text { on day } \\
\text { two and three until } \\
\text { appointment }\end{array}$ & $\begin{array}{l}78 \%(89 / 1 / 4) \text { of patients } \\
\text { induced with buprenorphine } \\
\text { in the ED were still in } \\
\text { addiction treatment at } 30 \text { - } \\
\text { day mark when compared to } \\
37 \%(38 / 102) \text { in the referral } \\
\text { only group }\end{array}$ \\
\hline $\begin{array}{l}\text { Duber et al } \\
2018^{32}\end{array}$ & $\begin{array}{l}\text { Clinical review summarizing } \\
\text { strategies for identifying, } \\
\text { treating, and transitioning } \\
\text { patients with OUD }\end{array}$ & $\begin{array}{ll}- & \text { COWS } \\
- & \text { Induction } \\
& \text { threshold not } \\
& \text { specified }\end{array}$ & $\begin{array}{l}\text { Initial: } 2-4 \mathrm{mg} \\
\text { (but can start } \\
\text { at } 8 \mathrm{mg} \text { ) } \\
\text { Second: } \\
2-4 \mathrm{mg} \text { if } \\
\text { symptoms } \\
\text { persist } \\
\text { Max: } 8-12 \mathrm{mg} \\
\text { (increase if } \\
\text { heavy user) }\end{array}$ & $\begin{array}{l}\text { - Recommend SOAPP-R or } \\
\text { NIDA-m-ASSiST for } \\
\text { screening of OUD in the } \\
\text { ED } \\
\text { - Follow up appoints should } \\
\text { happen ASAP within } 72 \\
\text { hours } \\
\text { - There needs to be } \\
\text { a robust bridge between } \\
\text { ED and MAT } \\
\text { - Warm hand-offs utilizing } \\
\text { social workers }\end{array}$ & $\mathrm{N} / \mathrm{A}$ \\
\hline $\begin{array}{l}\text { Dunkley } \\
\text { et al } \\
2019^{19}\end{array}$ & $\begin{array}{l}\text { Retrospective cohort study } \\
\text { of I } 8 \text { patients with OUD } \\
\text { investigating the feasibility of } \\
\text { using buprenorphine in an } \\
\text { ED CDU setting and } \\
\text { retention of patients in MAT } \\
\text { programs }\end{array}$ & $\begin{array}{l}\text { - Presence of } \\
\text { DSM-5 OUD } \\
\text { determined by } \\
\text { toxicology } \\
\text { fellow } \\
\text { - cOWS score } \geq \\
10\end{array}$ & $\begin{array}{l}\text { Initial: } 2-0.5 \mathrm{mg} \\
\text { of } \\
\text { buprenorphine- } \\
\text { naloxone } \\
\text { Max: } 8: 2 \mathrm{mg} \\
\text { maximum dose }\end{array}$ & $\begin{array}{l}\text { Discharge at } 24 \text { hours } \\
\text { with follow up appoint- } \\
\text { ment in the MAT clinic } \\
\text { - MAT clinic with same pro- } \\
\text { vider who initiated bupre- } \\
\text { norphine in the ED-CDU }\end{array}$ & $\begin{array}{l}63 \%(n=12 / 19) \text { of patients } \\
\text { induced in ED attend initial } \\
\text { MAT visit. } 47 \%(9 / 19) \text { still } \\
\text { active at I month, and } 21 \% \\
(4 / 9) \text { still active at } 6 \text { months. }\end{array}$ \\
\hline
\end{tabular}

(Continued) 
Table 2 (Continued).

\begin{tabular}{|c|c|c|c|c|c|}
\hline Author & Method & $\begin{array}{l}\text { Clinical } \\
\text { Assessment } \\
\text { and Induction } \\
\text { Threshold }\end{array}$ & Dosing & Plan for Follow-Up & Outcomes \\
\hline $\begin{array}{l}\text { Kaucher } \\
\text { et al } \\
2019^{20}\end{array}$ & $\begin{array}{l}\text { Retrospective study of } 219 \\
\text { patients with OUD } \\
\text { investigating the retention of } \\
\text { patients in MAT programs } \\
\text { after induction of } \\
\text { buprenorphine in the ED }\end{array}$ & $\begin{array}{l}\text { - } \text { cows } 6-12 \\
\text { - } \text { coWs } \geq 13\end{array}$ & $\begin{array}{l}\text { Initial COWS } \\
\text { 6-12: } 2-4 \mathrm{mg} \\
\text { Initial COWS } \\
\text { I3: } 4-6 \mathrm{mg} \\
\text { Max: } 16 \mathrm{mg}\end{array}$ & $\begin{array}{l}\text { - Next day MAT follow up } \\
\text { with intranasal naloxone } \\
\text { and SBIRT resources } \\
\text { - If X-waivered: prescribe } \\
\text { up to buprenorphine/ } \\
\text { naloxone } 16 \mathrm{mg} \text { if } \\
\text { next day appointment } \\
\text { cannot be made }\end{array}$ & $\begin{array}{l}\text { At the } 30 \text {-day mark, } 49.3 \% \\
(108 / 219) \text { of patients } \\
\text { induced with buprenorphine } \\
\text { were retained in MAT } \\
\text { programs. }\end{array}$ \\
\hline $\begin{array}{l}\text { Srivastava } \\
\text { et al } \\
2019^{21}\end{array}$ & $\begin{array}{l}\text { RCT of } 26 \text { patients } \\
\text { investigating effectiveness of } \\
\text { buprenorphine vs clonidine } \\
\text { in retaining patients in MAT } \\
\text { program }\end{array}$ & $\begin{array}{l}\text { - Presence of } \\
\text { opioid } \\
\text { withdrawal } \\
\text { - Optional } \\
\text { cows }\end{array}$ & $\begin{array}{l}\text { Initial: Not } \\
\text { specified } \\
\text { Maximum: } \\
12 \mathrm{mg}\end{array}$ & $\begin{array}{l}\text { - 5-day supply of buprenor- } \\
\text { phine ( } 8 \mathrm{mg} / \text { day) dis- } \\
\text { pensed at one time in } \\
8 \mathrm{mg} \text { tablets } \\
\text { - Map given to patients } \\
\text { showing nearest phar- } \\
\text { macy open } 7 \text { days a week } \\
\text { - Printed information and } \\
\text { map with location of } \\
\text { addiction facility }\end{array}$ & $\begin{array}{l}\text { Patients induced with } \\
\text { buprenorphine in the ED } \\
\text { were more likely to receive } \\
\text { opioid agonist treatment at } \\
\text { I-month mark when } \\
\text { compared to clonidine, } 62 \% \\
(8 / 13) \text { vs } 8 \%(I / I 3) \text {, } \\
\text { respectively. }\end{array}$ \\
\hline $\begin{array}{l}\text { Reuter } \\
\text { et al } \\
2019^{23}\end{array}$ & $\begin{array}{l}\text { Scientific abstract detailing } \\
\text { a prospective study of } 2 / 2 \\
\text { patients with OUD who } \\
\text { were treated with } \\
\text { buprenorphine in the ED } \\
\text { and followed into MAT } \\
\text { programs }\end{array}$ & $\begin{array}{l}\text { - } \text { cows } \\
\text { - Induction } \\
\text { threshold not } \\
\text { specified }\end{array}$ & $\begin{array}{l}\text { Initial: } 4 \mathrm{mg} \\
\text { Second: } 4 \mathrm{mg} \\
\text { dose if COWS } \\
>8\end{array}$ & $\begin{array}{l}\text { - Patients discharged to } \\
\text { "close opioid treatment } \\
\text { provider" for next day } \\
\text { follow up } \\
\text { - Patient can come back to } \\
\text { ED for buprenorphine } \\
\text { treatment on weekends } \\
\text { and holidays }\end{array}$ & $\begin{array}{l}\text { Included } 89 \text { patients, only } 7 \text { I } \\
\text { actually began MAT. } 83 \% \\
\text { (59/7I) of patients went to } \\
\text { first follow up appointment, } \\
\text { and of those } 59,95 \% \text { (56/59) } \\
\text { were still in program at } 6 \\
\text { months }\end{array}$ \\
\hline $\begin{array}{l}\text { Melnick } \\
\text { et al } \\
2019^{27}\end{array}$ & $\begin{array}{l}\text { Planned randomized trial to } \\
\text { be carried out in } 20 \mathrm{ED} \\
\text { across } 5 \text { healthcare systems }\end{array}$ & $\begin{array}{l}\text { - Presence of } \\
\text { DSM-5 OUD } \\
\text { COWS } \geq 8 \\
\text { COWS < } 8 \\
\text { consider unob- } \\
\text { served induc- } \\
\text { tion and } \\
\text { referral }\end{array}$ & $\begin{array}{l}\text { Initial COWS } \\
\text { 8-12: } 4 \mathrm{mg} \\
\text { Initial COWS } \geq \\
\text { I3: Consider } \\
8 \mathrm{mg} \\
\text { Max: Not } \\
\text { specified }\end{array}$ & $\begin{array}{l}\text { - If } \mathrm{X} \text {-waivered: physician } \\
\text { prescribes } 16 \mathrm{mg} \text { of } \\
\text { buprenorphine for } \\
\text { each day until appoint- } \\
\text { ment with outside addic- } \\
\text { tion treatment } \\
\text { - If not X-waivered: con- } \\
\text { sider instructing patient } \\
\text { to return to ED for } 2 \\
\text { days of } 16 \mathrm{mg} \text { of bupre- } \\
\text { norphine dosing with } \\
\text { referral for addiction } \\
\text { treatment } \\
\text { Warm handoff to outside } \\
\text { addictions provider within } \\
24-72 \text { hours }\end{array}$ & Not yet published \\
\hline
\end{tabular}

(Continued) 
Table 2 (Continued).

\begin{tabular}{|c|c|c|c|c|c|}
\hline Author & Method & $\begin{array}{l}\text { Clinical } \\
\text { Assessment } \\
\text { and Induction } \\
\text { Threshold }\end{array}$ & Dosing & Plan for Follow-Up & Outcomes \\
\hline $\begin{array}{l}\text { Cisewski } \\
\text { et al } \\
2019^{31}\end{array}$ & $\begin{array}{l}\text { Narrative review that } \\
\text { discusses the approach to } \\
\text { initiating buprenorphine use } \\
\text { in the ED for opioid-abuse } \\
\text { recovery }\end{array}$ & - coWs $>7$ & $\begin{array}{l}\text { Initial: } 4 \mathrm{mg} \\
\text { Max: } 16 \mathrm{mg}\end{array}$ & $\begin{array}{l}\text { - Provide patient with MAT } \\
\text { clinic information within } \\
48-72 \text { hours } \\
\text { - If X-waivered: prescribe } \\
\text { 3-day course at equal } \\
\text { dosage to that used in the } \\
\text { ED (8-16mg) } \\
\text { - If possible, discharge } \\
\text { patient with bridging dose } \\
\text { (2-4mg) }\end{array}$ & $\mathrm{N} / \mathrm{A}$ \\
\hline $\begin{array}{l}\text { Herring } \\
\text { et al } \\
2019^{34}\end{array}$ & $\begin{array}{l}\text { Review article analyzing } \\
\text { treatment options and } \\
\text { different induction protocols } \\
\text { for the use of } \\
\text { buprenorphine in an ED } \\
\text { setting }\end{array}$ & $\begin{array}{l}\text { - Uncomplicated } \\
\text { Opioid } \\
\text { Withdrawal } \\
\text { COWS } \geq 8 \\
\text { - COWS < } 8 \\
\text { reassess in I-2 } \\
\text { hours }\end{array}$ & $\begin{array}{l}\text { Initial: 4-8 mg } \\
\text { (based on } \\
\text { severity) } \\
\text { Max: } 32 \mathrm{mg}\end{array}$ & $\begin{array}{l}\text { - If X-waivered: prescribe } \\
\text { max } 16 \mathrm{mg} \text { SL buprenor- } \\
\text { phine/naloxone for 3-7 } \\
\text { days or until appointment } \\
\text { with outside addiction } \\
\text { facility } \\
\text { - Provide patients with the } \\
\text { highest level of care navi- } \\
\text { gation and shortest } \\
\text { appointment wait time }\end{array}$ & N/A \\
\hline $\begin{array}{l}\text { Bogan et al } \\
2020^{22}\end{array}$ & $\begin{array}{l}\text { Article reviewing the } \\
\text { implementation of an } \\
\text { emergency department- } \\
\text { initiated buprenorphine } \\
\text { program aimed at treating } \\
\text { opioid use disorder }\end{array}$ & $\begin{array}{l}\text { - } \text { Presence of } \\
\text { OUD } \\
\text { - COWS }>8 \\
\text { - If COWS < } 8 \\
\text { patients were } \\
\text { excluded }\end{array}$ & $\begin{array}{l}\text { Initial: } 8 \mathrm{mg} \\
\text { buprenorphine } \\
\text { or } 8: 2 \mathrm{mg} \\
\text { buprenorphine- } \\
\text { naloxone } \\
\text { Maximum: Not } \\
\text { specified }\end{array}$ & $\begin{array}{l}\text { - All patients with OUD we } \\
\text { offered naloxone kit upon } \\
\text { discharge from ED } \\
\text { - Patient navigator arranged } \\
\text { outpatient follow up } \\
\text { within } 24 \text { hours of } \\
\text { discharge }\end{array}$ & $\begin{array}{l}78 \% \text { ( } I 87 / 24 I) \text { showed up } \\
\text { for initial outpatient visit. } \\
59 \% \text { (III/I87) of those who } \\
\text { showed up for initial visit } \\
\text { were still in treatment at } 30 \\
\text { days post discharge. Of the } \\
535 \text { patients eligible for } \\
\text { naloxone kits } 39 \% \text { (209/535) } \\
\text { elected to receive a kit. }\end{array}$ \\
\hline $\begin{array}{l}\text { Jaeger and } \\
\text { Fuehrlein } \\
2020^{33}\end{array}$ & $\begin{array}{l}\text { Narrative review of the } \\
\text { safety and efficacy of } \\
\text { buprenorphine induction } \\
\text { that is started in the ED }\end{array}$ & $\begin{array}{l}\text { OUD estab- } \\
\text { lished through } \\
\text { history and } \\
\text { physical } \\
\text { - COWS > } 8 \text { or } \\
\text { subjectively } \\
\text { ready }\end{array}$ & $\begin{array}{l}\text { Initial: } 2 \text { or } \\
4 \mathrm{mg} \\
\text { Max: Not } \\
\text { specified }\end{array}$ & $\begin{array}{l}\text { - Connecticut veterans hos- } \\
\text { pital: Patients present daily } \\
\text { to detox and stabilization } \\
\text { service regardless of out- } \\
\text { patient/inpatient or inten- } \\
\text { sive outpatient follow-up }\end{array}$ & $\mathrm{N} / \mathrm{A}$ \\
\hline $\begin{array}{l}\text { Carroll } \\
\text { et al } \\
2020^{35}\end{array}$ & $\begin{array}{l}\text { Case-series that looks at the } \\
\text { feasibility of using EMS to } \\
\text { assess and treat OUD with } \\
\text { buprenorphine in the field } \\
\text { under the direction of } \\
\text { a supervising physician }\end{array}$ & 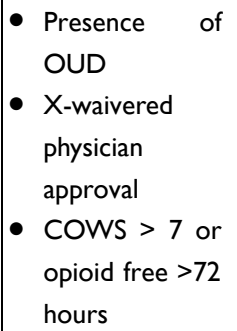 & $\begin{array}{l}\text { Initial: } 16 \mathrm{mg} \\
\text { Maximum: } \\
24 \mathrm{mg}\end{array}$ & $\begin{array}{l}\text { - Patients may either be } \\
\text { admitted to ED or refuse } \\
\text { further care } \\
\text { - All patients provided with } \\
\text { resources and next-day } \\
\text { MAT clinic appointment }\end{array}$ & $\begin{array}{l}\text { I8 patients were } \\
\text { administered buprenorphine } \\
\text { through this protocol. } 100 \% \\
(18 / 18) \text { demonstrated } \\
\text { improvement of symptoms. } \\
0 \%(0 / / 8) \text { demonstrated } \\
\text { precipitated withdrawal. }\end{array}$ \\
\hline
\end{tabular}

Abbreviations: CDU, clinical decision unit; COWS, Clinical Opiate Withdrawal Scale; MINI, Mini-international Neuropsychiatric Interview; OOWS, Objective Opiate Withdrawal Scale; OUD, opioid use disorder; RCT, randomized control trial; SBIRT, screening brief intervention, and referral for treatment; SOWS, Subjective Opiate Withdrawal Scale. 
based on a COWS score of greater than 8. Emergency clinicians can use either buprenorphine or a buprenorphinenaloxone, which are pharmacologically equivalent in the ED as naloxone is not orally bioavailable. In the United States, clinicians do not need a license waiver ("X-waiver") to prescribe medication for induction in a hospital setting. A waiver is only required to write an outpatient prescription including for any prescriptions written on discharge from the ED. The need for a waiver is a barrier for implementing OUD treatment programs with buprenorphine: only $2.2 \%$ of United States physicians have waivers to prescribe buprenorphine for OUD. ${ }^{36}$

Clinicians should also consider giving patients with OUD a prescription for intranasal or intramuscular naloxone to take home with them when discharged. When giving patients naloxone upon discharge is done in the context of a take-home-Naloxone program the number of opioidbased overdoses is significantly reduced. ${ }^{35}$ This harm reduction intervention may be life-saving not only for the patient at risk of opioid overdose but also for acquaintances of the patient - in one survey study, 53\% of ED patients with OUD had witnessed another person overdosing. ${ }^{37}$ If naloxone is offered, patients should be offered training and a filled prescription, as fill rates of ordered prescriptions are low. While several studies and a review endorse this practice, another review of EDdistributed naloxone found that the high variability of the implementation methods between these studies highlights a need for further research to determine best-practices. ${ }^{38}$

\section{Adverse Effects of Induction}

Buprenorphine is a safe and well tolerated medication. Several studies described side effects of buprenorphine induction in the ED. However, like full opioid agonists, buprenorphine can cause side effects such as constipation, nausea, vomiting, headache, and drowsiness in addition to the aforementioned risk of precipitated withdrawal. Research studies found these side effects to be relatively infrequent. Adverse effects of induction in the ED included precipitated withdrawal, ${ }^{13,20,31,33,34}$ sedation, ${ }^{31,34}$ QT prolongation (lengthening of a segment of the heart beat that can lead to arrhythmias), ${ }^{31,32}$ and potential P450 medication interactions. $^{32}$ No studies reported adverse events during follow-up periods after the ED induction.

\section{Follow-Up Arrangements After Induction}

Follow-up arrangements varied by study, and there were no comparative studies looking at the different follow-up interventions separately from buprenorphine treatment. Some studies described X-waivered ED providers prescribing a 3-day supply of buprenorphine-naloxone to bridge patients to outpatient care ci,23,31,34 $^{13}$ medicationassisted therapy (MAT) clinics. $^{31-33}$ In some cases, the prescribing physician in the ED may also see the patient in clinic. ${ }^{19}$ More intensive follow-up support includes coordination with psychological or case management services in the ED. ${ }^{23,32-34}$ and warm handoffs with social workers and case managers are a particularly popular choice in EDs. ${ }^{27,29,32,39,40}$ Recommendations for followup arrangements included having ED personnel make outpatient MAT appointments for patients ${ }^{32,34}$ and having follow-up within-network such as with a "hub and spoke" model. ${ }^{20,41}$ The timing of follow-up differed among articles, but all arranged follow-up within 72 hours between ED discharge and initial MAT followup visit. ${ }^{27,31,32,34}$ Table 3 summarizes the different care transition models described in the literature.

Optimal follow-up arrangements depend in large part on a particular ED's community setting. Emergency providers should feel confident that a 3-day course of buprenorphine-naloxone may be safely prescribed on discharge to facilitate connection to follow-up care. The availability of a care coordinator who can make explicit follow-up arrangements is optimal.

\section{Alternatives to Buprenorphine Induction}

The search strategy revealed several treatment options for patients with OUD besides buprenorphine induction including methadone continuation, ${ }^{31-33}$ clonidine for withdrawal symptoms, ${ }^{21,32,34,42}$ or crystalloid replacement combined with adjunctive symptomatic treatments. ${ }^{31,32,34,42}$ Aside from the aforementioned trial finding buprenorphine superior to clonidine for opioid withdrawal, ${ }^{21}$ no studies compared alternative active treatments to buprenorphine in emergency settings.

One medical treatment option of potential interest to emergency clinicians may be naltrexone. Naltrexone is an opioid antagonist with mixed evidence for use treating OUD outside emergency settings; no studies have assessed the drug's utility in emergency practice. Naltrexone is available in multiple formulations including orally and in a long-acting injectable. While naltrexone itself is quite safe, the longacting formulation has not demonstrated substantial efficacy for reducing opioid use, ${ }^{43}$ and the oral formulation was not considered effective in a meta-analysis of 13 studies. ${ }^{44}$ One finding of these studies was that participants discontinued 
Table 3 Models of Care for Transition from the Emergency Department to Medication-Assisted Treatment Programs

\begin{tabular}{|c|c|}
\hline Author & Transition Model \\
\hline $\begin{array}{l}\text { Kaucher et al } \\
2019^{20}\end{array}$ & $\begin{array}{l}\text { - Hub-and-spoke model where ED and hospital's onsite MAT center served as hub and affiliated community providers were } \\
\text { the spokes } \\
\text { - Patients initially treated at a hub } \\
\text { - Patients initiated in the ED were given next day follow up at the MAT clinic }\end{array}$ \\
\hline Kelly et al $2019^{29}$ & $\begin{array}{l}\text { - Social work follow-up in the ED after initial induction with buprenorphine } \\
\text { - Patients were screened for this study by MI and DSM-V to find patients with OUD who were motivated to engage in } \\
\text { treatment } \\
\text { - SW worked with surrounding community teams to set up follow-up care for patients } \\
\text { - Outcome of study was patient engagement } 30 \text { days post ED course } \\
\text { - Also looked at ED length of stay, success rate of patients showing up to Ist outpatient appointment, and median number of } \\
\text { days until this first outpatient follow up }\end{array}$ \\
\hline $\begin{array}{l}\text { Ahmed et al } \\
2019^{39}\end{array}$ & $\begin{array}{l}\text { - Although not implemented, stakeholders suggest three recommendations for a successful warm hand-off: } \\
\text { - Designing "an automated, rapid, and flexible" referral system } \\
\text { - Quality assurance through aggregate metrics } \\
\text { - Providing urgent follow up with community clinics }\end{array}$ \\
\hline Sholl et al $2019^{40}$ & $\begin{array}{l}\text { - Social work driven process designed to lessen the burden on physicians in terms of arranging follow up for patients to } \\
\text { community resources } \\
\text { - MAT centers, primary care, etc. } \\
\text { - Patients identified for eligibility for social worker by provider referral and nurse screening } \\
\text { - Physician involvement was decreased, only including brief screening and buprenorphine prescribing until follow up } \\
\text { appointment }\end{array}$ \\
\hline $\begin{array}{l}\text { Kawasaki et al } \\
2019^{41}\end{array}$ & $\begin{array}{l}\text { - All ED physicians waivered } \\
\text { - ED social workers schedule appointments within I-2 days } \\
\text { - ED has a reliable after-care model consisting of a series of "spoke" clinics connected to a central "hub" } \\
\text { - Both spokes and the hub provide pharmacy and psychiatric services } \\
\text { - Higher acuity patients and more severe patients receive treatment at the hub. } \\
\text { - Integrated so that spoke clinics can refer to hub with minimal wait time } \\
\text { - If spoke or hub does not have time to initiate, patients can initiate at a partnered urgent care centers (bridge clinics) and } \\
\text { - return to spoke after } \\
\text { - Inis model allows for shorter wait time for higher risk patients }\end{array}$ \\
\hline
\end{tabular}

naltrexone treatment at a higher rate, and significantly sooner than those participants who were placed on a sublingual preparation of buprenorphine-naloxone. Another study found that people on naltrexone were twice as likely to discontinue treatment "for any reason" compared with "adverse events." 45 However, the authors of this paper did not fully specify what reasons for discontinuation they included under "for any reason," but mentioned that some of the reasons included relapse, dropping out of treatment programs, and feeling that the medication was not adequately controlling their cravings. One potential downside of the early discontinuation discussed in these studies is an increase a person's risk of accidental overdose if they begin using non-prescribed opioids because they have a reduced opioid tolerance after using Naloxone. ${ }^{43-45}$ Therefore, efforts to improve adherence to naltrexone may enhance its efficacy and increase its value for emergency practices that lack strong partners to support aftercare for buprenorphine induction. Naltrexone may also be of particular benefit for adolescents with OUD. ${ }^{46}$

\section{Barriers to Implementing Induction Programs}

ED-based buprenorphine induction faces logistical, systemic, and clinical challenges to implementation. Physicians have cited lack of clinical familiarity prescribing buprenorphine, concerns about legal regulations, and the impact on ED length of stay and patient flow as reasons for not initiating 
Table 4 Barriers to Buprenorphine Induction in the Emergency Department

\begin{tabular}{|c|c|c|}
\hline Author & Method & Barriers to Induction \\
\hline $\begin{array}{l}\text { Medcalf et al } \\
2015^{51}\end{array}$ & $\begin{array}{l}27 \text { ED physician responders to a } 24 \text {-question survey sent to } \\
\text { emergency physicians in one academic ED }\end{array}$ & $\begin{array}{l}\text { - Unfamiliarity with standardized methods of severity for acute } \\
\text { opioid withdrawal. } \\
\text { - Unfamiliar with timing of buprenorphine in relation to mod- } \\
\text { - Unate opioid withdrawal } \\
\text { - Unfamiliarity with prescribing indications and nuances } \\
\text { - Uncertainty with side effects }\end{array}$ \\
\hline $\begin{array}{l}\text { Hawk et al } \\
2019^{47}\end{array}$ & $\begin{array}{l}\text { Organizational Readiness to Change Assessment administered } \\
\text { in three different hospitals settings. Followed by in-person focus } \\
\text { groups with ED physicians, PA/APRNs, nurses, social workers, } \\
\text { and community providers }\end{array}$ & $\begin{array}{l}\text { - Lack of experience with buprenorphine } \\
\text { - Difficulties with workflow integration } \\
\text { - Increased time needed to treat these patients. } \\
\text { - Limited knowledge of available treatment options for patients }\end{array}$ \\
\hline $\begin{array}{l}\text { Hernandez- } \\
\text { Meier } 2019^{48}\end{array}$ & $\begin{array}{l}2 \mathrm{I} \text {-question survey sent to } 98 \text { providers including physicians, } \\
\text { physicians' assistants, and nurse practitioners }\end{array}$ & $\begin{array}{l}\text { - Gaps in knowledge and understanding of buprenorphine } \\
\text { induction in the ED } \\
\text { - Need for further education in pharmacology, dosages, effi- } \\
\text { cacy, outcome information, and legal implications }\end{array}$ \\
\hline $\begin{array}{l}\text { Lowenstein } \\
\text { et al } 2019^{49}\end{array}$ & $\begin{array}{l}\text { Cross-sectional survey of physicians in two EDs. These barriers } \\
\text { are physician perceived }\end{array}$ & $\begin{array}{l}\text { - Lack of comfort counseling about buprenorphine } \\
\text { - Lack of comfort ordering buprenorphine } \\
\text { - Regulatory concerns } \\
\text { - Time constraints } \\
\text { - Concerns about diversion, misuse, and safety } \\
\text { These concerns differed between X-waiver and non- } \\
\text { X-waivered physicians }\end{array}$ \\
\hline $\begin{array}{l}\text { Martin et al } \\
2019^{50}\end{array}$ & $\begin{array}{l}\text { Semi-structured interviews with ED providers in a hospital with } \\
\text { MAT protocol. Also interviewed } 10 \text { patients with OUD }\end{array}$ & $\begin{array}{l}\text { - Time pressure and lack of cues to know what to ask about } \\
\text { - Opioid misuse } \\
\text { - Uncertainty with treatment protocols } \\
\text { - Uncertainty about responsibility of OUD treatment } \\
\text { - Patient focus on present not future } \\
\text { - Misma surrounding treatment programs } \\
\text { - Mistrust of health system }\end{array}$ \\
\hline $\begin{array}{l}\text { Wiercigroch } \\
\text { et al } 2019^{52}\end{array}$ & $\begin{array}{l}\text { Semi- structured interviews of } 19 \text { self-selected physicians at } \\
\text { single Toronto ED }\end{array}$ & $\begin{array}{l}\text { - Provider inexperience causing missed subtle presentations of } \\
\text { - withdrawal } \\
\text { - Lacking feedback on treatment effectiveness } \\
\text { - Uncertainty about protocol from nursing staff } \\
\text { - Fast paced ED limits amount of time for counseling } \\
\text { - ED environment discourages taking up a bed to wait for } \\
\text { - withdrawal symptoms } \\
\text { - Worries about precipitating withdrawal } \\
\text { setting }\end{array}$ \\
\hline $\begin{array}{l}\text { Hawk, } \\
\text { McCormack } \\
\text { et al } 2019^{47}\end{array}$ & $\begin{array}{l}\text { Focus groups of patients with OUD chosen from recent ED } \\
\text { visits. } 29 \text { patients from Baltimore, NYC, Cincinnati, and Seattle. }\end{array}$ & $\begin{array}{l}\text { - Key themes from the focus groups } \\
\text { - Perception that ED staff did not understand OUD as } \\
\text { a disease } \\
\text { - Dehumanizing experiences in the past due to OUD } \\
\text { Long history of feeling stigmatized }\end{array}$ \\
\hline $\begin{array}{l}\text { Dora-Laskey } \\
\text { and Sadler } \\
2019^{57}\end{array}$ & $\begin{array}{l}\text { Compared locations of MATs to that of emergency } \\
\text { departments in Michigan. }\end{array}$ & $\begin{array}{l}\text { - Found that } 43.5 \% \text { of EDs had a MAT facility within } 5 \text { miles } \\
\text { - Found that } 50.4 \% \text { had a MAT facility within } 10 \text { miles } \\
\text { Concluded that only half of Michigan's EDs were within } 10 \\
\text { miles of a MAT, limiting patients' access to long term care }\end{array}$ \\
\hline
\end{tabular}


ED-based induction programs. ${ }^{47-52}$ Prescribers are also concerned about misuse and diversion among patients. ${ }^{49}$ These concerns are not without cause: a review of patients treated in community settings suggest $16-46 \%$ had misused buprenorphine and $18-28 \%$ diverted medications. ${ }^{53}$ The most frequent reasons for misuse were continuing opioid use habits (eg, injecting or snorting medication), addressing concern for under-dosing, alleviating withdrawal, achieving positive effects (eg, euphoria), and relieving negative states. Reasons for diversion of buprenorphine were peer pressure, desire to help an addicted friend or family member, and making money. Use of buprenorphine-naloxone decreases the risk of misuse and diversion compared to buprenorphine without naloxone. When compared to methadone, the rates of misuse and diversion for buprenorphine are much lower. ${ }^{54}$ These risks of misuse and diversion must be weighed with the substantial morbidity and mortality of untreated OUD.

Another barrier that patients have reported is their reluctance to accept treatment due to fear of stigmatization and general mistrust in the health system. ${ }^{47,50}$ ED administrators have voiced concern that offering ED-based buprenorphine induction might increase the volume of patients presenting with substance use disorders, but an analysis of ED volumes after introduction of induction services at one ED suggests this not to be the case. ${ }^{55}$

In rural areas, the physical distance between ED and medicated-assisted treatment (MAT) facilities and sparse distribution of $\mathrm{X}$-waivered providers to provide follow-up care pose major barriers to successful buprenorphine programs. $^{56,57}$ In the US, $56 \%$ of rural counties lack a X-waivered physician to prescribe buprenorphine. ${ }^{56}$ Some interventions to ameliorate these barriers have been described: one program trained first responders to administer buprenorphine in the community. ${ }^{35}$ Table 4 summarizes barriers to implementation of ED-based buprenorphine induction.

\section{Discussion}

Buprenorphine is a safe and effective treatment for patients with OUD in the ED. Multiple studies demonstrate improved rates of follow-up in substance treatment and decreased illicit substance use among patients receiving buprenorphine induction versus usual care. ED administrators and clinicians should be familiar with buprenorphine induction and build care processes to make induction feasible within the limitations of community resources.
Despite the strong evidence supporting induction programs, there remain notable gaps in knowledge. The quality of included studies varied in quality as well as scope. Insufficient knowledge exists as to optimal ED dosing regimens, psychosocial interventions that improve followup from the ED, and which patients are at risk for adverse events and sub-optimal outcomes. No included studies describe buprenorphine use for detoxification in the ED setting (rather than initiation of maintenance treatment.) Moreover, studies are limited to a short follow-up timeframe-typically initial visit and 30 day follow-up-and continued care support is almost certainly necessary to improve outcomes. Indeed, extended follow-up of the original D'Onofrio study revealed that intervention patients receiving ED-based induction were not more likely to remain in treatment by 6 months than those in control cohorts. $^{25}$

Effectiveness research of buprenorphine induction may include more heterogeneous populations including with comorbid psychiatric illness. In practice, clinicians are anecdotally challenged to manage inductions in the context of complex clinical scenarios such as after recent naloxone reversals, while misusing long-acting oral opioids, or in the context of polysubstance withdrawal. ${ }^{4,50-52}$ More evidence is needed to inform safe, effective management of these patient presentations. One such challenging example is the malingering patient; little guidance is provided by the scientific evidence of treatment for these patients despite clinicians' frequently cited concerns around the risk of buprenorphine misuse.

Maximizing the potential for ED buprenorphine treatment will require further research on optimal induction protocols - particularly for complex presentations - and psychosocial interventions to mitigate barriers to followup. Clear barriers were found among physicians and health systems in implementing ED induction programs, but no studies described strategies to ameliorate cultural and institutional resistance to program development. Indeed, many of the concerns cited by clinicians related to ambiguous presentations of opioid withdrawal, impact on length of ED stay, and safety treatment of highly co-morbid patients remain unanswered by the literature. In response to these concerns, a new multi-site pragmatic trial is studying how a package of systematic interventions, including incorporating induction protocols into the electronic medical record, may facilitate access to buprenorphine treatment through the ED. ${ }^{27}$ 
These outstanding questions do not obscure the fact that patients with OUD will continue to present to emergency medical services. The capacity to provide ED-based buprenorphine induction programs represents an important advancement in the care of these patients, and the lessons learned from these programs hold lessons for the treatment of other substance use disorders.

\section{Disclosure}

SA Simpson has received royalties from Taylor \& Francis for a clinical textbook and reports advisory group work for Impel Neuropharma, outside the submitted work. The other authors have no conflicts of interest or disclosures for this work.

\section{References}

1. National Center for Health Statistics. Provisional Drug Overdose Death Counts 2019. https://www.cdc.gov/nchs/nvss/vsrr/drug-over dose-data.htm.

2. Bose J, Hedden S, Lipari R, Park-Lee E. Key Substance Use and Mental Health Indicators in the United States: Results from the 2017 National Survey on Drug Use and Health. Rockville, MD: Center for Behavioral Health Statistics and Quality, Substance Abuse and Mental Health Services Administration; 2017.

3. Agency for Healthcare Research and Quality. Health Care Costs and Utilization Project 2020. www.hcup-us.ahrq.gov/home.jsp. Accessed September 21, 2020.

4. American Psychiatric Assocation. Substance-related and addictive disorders. Diagnostic and Statistical Manual of Mental Disorders. 5th. Washingston. 2013.

5. National Institute of Drug Abuse. Substance Use Screen/Adapted NM Assist Tool:2015. https://www.drugabuse.gov/nidamed-medicalhealth-professionals/screening-tools-resources/american-psychiatricassociation-adapted-nida-modified-assist-tools. Accessed May 13, 2020.

6. Webster LR, Webster RM. Predicting aberrant behaviors in opioid-treated patients: preliminary validation of the Opioid Risk Tool. Pain Med. 2005;6(6):432-442. doi:10.1111/j.1526-4637.2005. 00072.x

7. Mattick RP, Breen C, Kimber J, Davoli M. Methadone maintenance therapy versus no opioid replacement therapy for opioid dependence. Cochrane Database Syst Rev. 2009;2009(3):Cd002209.

8. Russolillo A, Moniruzzaman A, Somers JM. Methadone maintenance treatment and mortality in people with criminal convictions: A population-based retrospective cohort study from Canada. PLoS Med. 2018;15(7):e1002625. doi:10.1371/journal.pmed.1002625

9. Farmani F, Farhadi H, Mohammadi Y. Associated Factors of Maintenance in Patients under Treatment with Methadone: A Comprehensive Systematic Review and Meta-Analysis. Addict Health. 2018;10(1):41-51.

10. Maremmani AGI, Pacini M, Maremmani I. What we have learned from the Methadone Maintenance Treatment of Dual Disorder Heroin Use Disorder patients. Int J Environ Res Public Health. 2019;16(3):3. doi: $10.3390 /$ ijerph 16030447

11. Nielsen S, Larance B, Degenhardt L, Gowing L, Kehler C, Lintzeris N. Opioid agonist treatment for pharmaceutical opioid dependent people. Cochrane Database Syst Rev. 2016;(5):Cd011117.

12. Sharma B, Bruner A, Barnett G, Fishman M. Opioid Use Disorders. Child and Adolescent Psychiatric Clinics of North America. 2016;25 (3):473-487. doi:10.1016/j.chc.2016.03.002
13. D'Onofrio G, O'Connor PG, Pantalon MV, et al. Emergency department-initiated buprenorphine/naloxone treatment for opioid dependence: a randomized clinical trial. JAMA. 2015;313 (16):1636-1644. doi:10.1001/jama.2015.3474

14. D'Onofrio G, Edelman EJ, Hawk KF, et al. Implementation facilitation to promote emergency department-initiated buprenorphine for opioid use disorder: protocol for a hybrid type III effectiveness-implementation study (Project ED HEALTH). Implement Sci. 2019;14(1):48. doi:10.1186/s13012-019-0891-5

15. Higgins J, Thomas J, Chandler J, et al. Cochrane Handbook for Systematic Reviews of Interventions. Cochrane. 2019;2:125.

16. Wells G, Shea B, O'Connell D, et al. The Newcastle-Ottawa Scale (NOS) for Assessing Quality of Nonrandomised Studies in Meta-Analyses. Ottawa Hospital Res Inst. 2013;23:2154.

17. McHugh ML. Interrater reliability: the kappa statistic. Biochem Med (Zagreb). 2012;22(3):276-282. doi:10.11613/BM.2012.031

18. Moher D, Liberati A, Tetzlaff J, Altman DG. Preferred reporting items for systematic reviews and meta-analyses: the PRISMA statement. PLoS Med. 2009;6(7):e1000097. doi:10.1371/journal. pmed. 1000097

19. Dunkley CA, Carpenter JE, Murray BP, et al. Retrospective Review of a Novel Approach to Buprenorphine Induction in the Emergency Department. J Emerg Med. 2019;57(2):181-186. doi:10.1016/j. jemermed.2019.03.029

20. Kaucher KA, Caruso EH, Sungar G, et al. Evaluation of an emergency department buprenorphine induction and medication-assisted treatment referral program. Am J Emerg Med. 2020;38(2):300-304. doi:10.1016/j.ajem.2019.158373

21. Srivastava A, Kahan M, Njoroge I, Sommer LZ. Buprenorphine in the emergency department: randomized clinical controlled trial of clonidine versus buprenorphine for the treatment of opioid withdrawal. Can Fam Physician. 2019;65(5):e214-e220.

22. Bogan C, Jennings L, Haynes L, et al. Implementation of emergency department-initiated buprenorphine for opioid use disorder in a rural southern state. J Subst Abuse Treat. 2020;112s:73-78. doi:10.1016/j. jsat.2020.02.007

23. Reuter Q, Smith G, McKinnon J, Varley J, Jouriles N, Seaberg D. Successful Medication-Assisted Treatment Program at a Community Emergency Department. Ann Emerg Med. 2019;74(4):S89. doi:10.1016/j.annemergmed.2019.08.393

24. Busch SH, Fiellin DA, Chawarski MC, et al. Cost-effectiveness of emergency department-initiated treatment for opioid dependence. Addiction. 2017;112(11):2002-2010. doi:10.1111/add.13900

25. D’Onofrio G, Chawarski MC, O'Connor PG, et al. Emergency Department-Initiated Buprenorphine for Opioid Dependence with Continuation in Primary Care: outcomes During and After Intervention. J Gen Intern Med. 2017;32(6):660-666. doi:10.1007/ s11606-017-3993-2

26. American College of Emergency Physicians. Buprenorphine Use in the Emergency Department Tool. ; 2018. https://www.acep.org/bupe

27. Melnick ER, Jeffery MM, Dziura JD, et al. User-centred clinical decision support to implement emergency department-initiated buprenorphine for opioid use disorder: protocol for the pragmatic group randomised EMBED trial. BMJ Open. 2019;9(5):e028488. doi:10.1136/bmjopen-2018-028488

28. Noormohammadi A, Forinash A, Yancey A, Crannage E, Campbell K, Shyken J. Buprenorphine Versus Methadone for Opioid Dependence in Pregnancy. Ann Pharmacother. 2016;50 (8):666-672. doi:10.1177/1060028016648367

29. Kelly T, Hoppe JA, Zuckerman M, Khoshnoud A, Sholl B, Heard K. A novel social work approach to emergency department buprenorphine induction and warm hand-off to community providers. Am J Emerg Med. 2020;38(6):1286-1290. doi:10.1016/j.ajem.2019.12.038

30. Wesson DR, Ling W. The Clinical Opiate Withdrawal Scale (COWS). J Psychoactive Drugs. 2003;35(2):253-259. doi:10.1080/ 02791072.2003.10400007 
31. Cisewski DH, Santos C, Koyfman A, Long B. Approach to buprenorphine use for opioid withdrawal treatment in the emergency setting. Am J Emerg Med. 2019;37(1):143-150. doi:10.1016/j. ajem.2018.10.013

32. Duber HC, Barata IA, Cioe-Pena E, et al. Identification, Management, and Transition of Care for Patients With Opioid Use Disorder in the Emergency Department. Ann Emerg Med. 2018;72 (4):420-431. doi:10.1016/j.annemergmed.2018.04.007

33. Jaeger S Jr, Fuehrlein B. Buprenorphine initiation to treat opioid use disorder in emergency rooms. J Neurol Sci. 2020;411:116716. doi:10.1016/j.jns.2020.116716

34. Herring AA, Perrone J, Nelson LS. Managing Opioid Withdrawal in the Emergency Department With Buprenorphine. Ann Emerg Med. 2019;73(5):481-487. doi:10.1016/j.annemergmed.2018.11.032

35. Carroll GG, Wasserman DD, Shah AA, et al. Buprenorphine Field Initiation of ReScue Treatment by Emergency Medical Services (Bupe FIRST EMS): A Case Series. Prehosp Emerg Care. 2020;1-6.

36. Rosenblatt RA, Andrilla CHA, Catlin M, Larson EH. Geographic and specialty distribution of US physicians trained to treat opioid use disorder. Ann Fam Med. 2015;13(1):23-26. doi:10.1370/afm.1735

37. Dwyer K, Walley AY, Langlois BK, et al. Opioid education and nasal naloxone rescue kits in the emergency department. West $J$ Emerg Med. 2015;16(3):381-384. doi:10.5811/westjem.2015.2.24909

38. Gunn AH, Smothers ZPW, Schramm-Sapyta N, Freiermuth CE, MacEachern M, Muzyk AJ. The Emergency Department as an Opportunity for Naloxone Distribution. West J Emerg Med. 2018;19 (6):1036-1042. doi:10.5811/westjem.2018.8.38829

39. Ahmed OM, Mao JA, Holt SR, et al. A scalable, automated warm handoff from the emergency department to community sites offering continued medication for opioid use disorder: lessons learned from the EMBED trial stakeholders. $J$ Subst Abuse Treat. 2019;102:47-52. doi:10.1016/j.jsat.2019.05.006

40. Sholl B, Heard K, Hoppe J, Capp R, Khoshnoud A, Holland C. Emergency department initiation of buprenorphine/naloxone with warm handoff to community care. Acad Emerg Med. 2019;26: S131.

41. Kawasaki S, Francis E, Mills S, Buchberger G, Hogentogler R, Kraschnewski J. Multi-model implementation of evidence-based care in the treatment of opioid use disorder in Pennsylvania. $J$ Subst Abuse Treat. 2019;106:58-64. doi:10.1016/j.jsat.2019. 08.016

42. Berg ML, Idrees U, Ding R, Nesbit SA, Liang HK, McCarthy ML. Evaluation of the use of buprenorphine for opioid withdrawal in an emergency department. Drug Alcohol Depend. 2007;86(2):239-244. doi:10.1016/j.drugalcdep.2006.06.014

43. Jarvis BP, Holtyn AF, Subramaniam S, et al. Extended-release injectable naltrexone for opioid use disorder: a systematic review. Addiction. 2018;113(7):1188-1209. doi:10.1111/add.14180

44. Minozzi S, Amato L, Vecchi S, Davoli M, Kirchmayer U, Verster A. Oral naltrexone maintenance treatment for opioid dependence. Cochrane Database Syst Rev. 2011;2011(4):Cd001333.
45. Donoghue K, Elzerbi C, Saunders R, Whittington C, Pilling S, Drummond C. The efficacy of acamprosate and naltrexone in the treatment of alcohol dependence, Europe versus the rest of the world: a meta-analysis. Addiction. 2015;110(6):920-930. doi:10.1111/add.12875

46. Camenga DR, Colon-Rivera HA, Muvvala SB. Medications for Maintenance Treatment of Opioid Use Disorder in Adolescents: A Narrative Review and Assessment of Clinical Benefits and Potential Risks. J Stud Alcohol Drugs. 2019;80(4):393-402. doi:10.15288/jsad.2019.80.393

47. Hawk K, McCormack R, Edelman EJ, et al. 260 Perceptions and Experiences of Emergency Department Patients With Opioid Use Disorder. Ann Emerg Med. 2019;74(4):S102. doi:10.1016/j. annemergmed.2019.08.218

48. Hernandez-Meier J, Good S, Zosel A. Emergency medicine provider attitudes toward and experiences with prescribing buprenorphine in the ED of a large academic metropolitan hospital. Clin Toxicol. 2019;57(10):1041-1042.

49. Lowenstein M, Kilaru A, Perrone J, et al. Barriers and facilitators for emergency department initiation of buprenorphine: A physician survey. Am J Emerg Med. 2019;37(9):1787-1790. doi:10.1016/j. ajem.2019.02.025

50. Martin A, Raja A, White B. Emergency department-initiated medication-assisted treatment: lessons learned one year after launch. Acad Emerg Med. 2019;26:S308.

51. Medcalf K, McGowan HM, Chu J, Klaiman MZ. Management of acute opioid withdrawal in the emergency department with buprenorphine/naloxone: an assessment of emergency physician knowledge and practice. Canadian J Emerg Med. 2015;17:S20-S21.

52. Wiercigroch D, Hoyeck P, Sheikh H, Hulme J. Management of opioid withdrawal: A qualitative examination of current practices and barriers to prescribing buprenorphine in a Canadian emergency department. Canadian J Emerg Med. 2019;21:S114.

53. Lofwall MR, Walsh SL. A review of buprenorphine diversion and misuse: the current evidence base and experiences from around the world. $J$ Addict Med. 2014;8(5):315-326. doi:10.1097/ADM.0000000000000045

54. Dasgupta N, Bailey EJ, Cicero T, et al. Post-marketing surveillance of methadone and buprenorphine in the United States. Pain Med. 2010;11(7):1078-1091. doi:10.1111/j.1526-4637.2010.00877.x

55. Jennings LK, Bogan C, McCauley JJ, et al. Rates of substance use disorder treatment seeking visits after emergency department-initiated buprenorphine. Am J Emerg Med. 2020;38(5):975-978. doi:10.1016/j. ajem.2020.02.011

56. Andrilla CHA, Moore TE, Patterson DG, Larson EH. Geographic Distribution of Providers With a DEA Waiver to Prescribe Buprenorphine for the Treatment of Opioid Use Disorder: A 5-Year Update. J Rural Health. 2019;35(1):108-112. doi:10.1111/jrh.12307

57. Dora-Laskey A, Sadler R. 261 Identifying Barriers to Emergency Department-Initiated Buprenorphine: A Spatial Analysis of Treatment Program Access in Michigan. Ann Emerg Med. 2019;74 (4):S102-S103. doi:10.1016/j.annemergmed.2019.08.219

\section{Publish your work in this journal}

The Open Access Emergency Medicine is an international, peerreviewed, open access journal publishing original research, reports, editorials, reviews and commentaries on all aspects of emergency medicine. The manuscript management system is completely online and includes a very quick and fair peer-review system, which is all easy to use. Visit http://www.dovepress.com/testimonials.php to read real quotes from published authors. 